\title{
Short-term effects of a Mediterranean-style dietary pattern on cognition and mental wellbeing: A systematic review of clinical trials
}

Latife Esgunoglu ${ }^{1}$, Amy Jennings ${ }^{1}$, Elizabeth Sanchia Connole ${ }^{2}$, Karen Joy Murphy ${ }^{2}$, Anne Marie Minihane ${ }^{1}$

${ }^{1}$ Department of Nutrition and Preventive Medicine, Norwich Medical School, University of East Anglia, UK

${ }^{2}$ Department of Nutrition and Dietetics, Clinical and Health Sciences, University of South Australia, Adelaide, Australia

Corresponding author: Latife Esgunoglu, Bob Champion Research and Education Building Colney Lane Norwich NR4 7UQ Norwich Norfolk UK, 1.esgunoglu@uea.ac.uk, +44 1603 287715

Short title: Review of Mediterranean diet, mood, cognition

[Disclosure statements, as outlined below. These must be included on the title page and not in the manuscript file, to enable double-blind reviewing; if the paper is accepted, they will be inserted into the manuscript during production. If any are not applicable, please state this.]

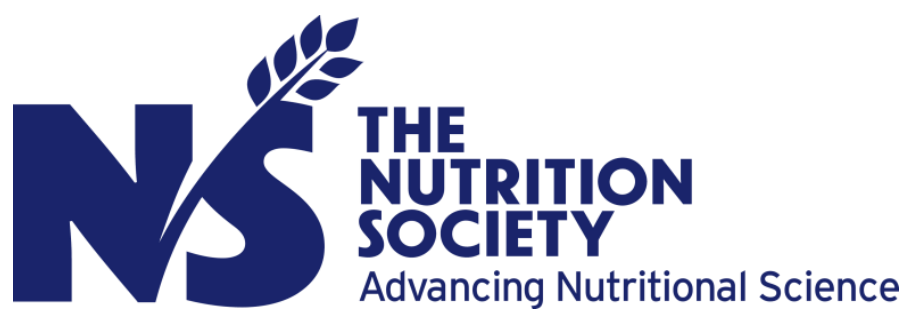

This peer-reviewed article has been accepted for publication but not yet copyedited or typeset, and so may be subject to change during the production process. The article is considered published and may be cited using its DOI

$10.1017 / \mathrm{S} 0007114521002567$

The British Journal of Nutrition is published by Cambridge University Press on behalf of The Nutrition Society 


\begin{abstract}
Background: Although the long-term effects of a Mediterranean-style dietary pattern (MDP) on cognition and overall mental wellbeing have been consistently described, the short-term effects of the MDP on cognitive performance, mood and anxiety have not been as widely reviewed. Objectives: The aims of this systematic review were to synthesise the evidence from randomised controlled trials (RCT) to examine whether a MDP can alter cognition and overall mental wellbeing in the short-term (up to 10 days). This will also be used to identify research gaps and to inform the design of future acute RCTs in the area. Methods: Ovid EMBASE, Ovid MEDLINE and Web of Science Core Collection were searched from inception to $8 / 12 / 2020$. The data was synthesised narratively with no quantitative synthesis. The detailed protocol is available on PROSPERO, with the registration number CRD42021221085. Results: A total of 3002 studies were initially identified. After the deduplication and screening stages, 4 studies ( 3 articles and 1 conference proceeding) were eligible to be included. Despite the very limited data obtained, the literature suggests that a MDP can improve cognition and mood in the short-term. Specifically, improvements in attention, alertness and contentment were consistently reported. Conclusion: A MDP appears a promising strategy to improve short-term cognitive and mental health. A limitation of this review is the small number of studies identified, therefore, future studies are required to confirm these initial novel findings, and to provide granularity as to which domains are most responsive and in which population subgroups.
\end{abstract}

Keywords: Mediterranean-style dietary pattern, mood, cognition, acute, short-term 


\section{Introduction}

With global ageing population demographics, the prevalence of cognitive disorders has surged ${ }^{(1)}$. The number of individuals living with dementia, which is a major cause of loss of independence and disability in older age, has doubled between 1990 to 2016, reaching 50 million worldwide ${ }^{(1)}$. In the UK, dementia is now the number one cause of death, responsible for about $15 \%$ of all-cause mortality ${ }^{(2)}$. Besides, dementia has an enormous economic burden, with the global cost expected to reach $\$ 2$ trillion by $2030^{(3)}$.

The prevalence of mild cognitive impairment (MCI), the transition phase prior to incident dementia, has been estimated to occur in $15-20 \%$ of the population aged over 60 years, with $8 \%$ to $15 \%$ progressing to dementia per year ${ }^{(4)}$. Subjective memory complaints (SMC), which is loosely defined as a state in which individuals present with 'self-reported' cognitive decline relative to their previous cognitive status (which is not diagnosed by objective standard tests) occurs in $50-80 \%$ of individuals aged 70 years or older ${ }^{(5)}$. SMC is linked to depression, anxiety and future Alzheimer's disease (AD) risk ${ }^{(5,6)}$. In addition to cognitive decline, mental disorders, including depression and anxiety disorders are prevalent, occurring in $3-5 \%$ of the global population ${ }^{(7)}$, and are one of the top three causes of non-fatal health loss in terms of years lived with disability ${ }^{(8)}$. Depression is also a risk factor for future dementia ${ }^{(9)}$.

Currently, $\mathrm{AD}$ and other dementias are irreversible with no effective treatments available to slow or reverse the condition. Therefore, behaviours (such as altered eating behaviour and nutrition status) which can prevent or delay progression of these conditions have the potential to dramatically reduce both individual risk and the population burden of the disease ${ }^{(10)}$. A Mediterranean-style dietary pattern (MDP) is emerging as having potential positive effects on mental health status. The diet is characterised by high consumption of extra virgin olive oil (EVOO) and plant-based foods such as fruits, vegetables, nuts, legumes, whole-grain cereals; low to moderate consumption of dairy products mainly yoghurt and cheese; fish consumed two to four times a week; low amounts of red meat; and moderate consumption of red wine mainly with meals ${ }^{(11)}$. EVOO, in addition to the being the major component of a MDP, has been shown to independently confer neuropsychiatric and cardiovascular benefits ${ }^{(12)}$, attributed to its high monounsaturated fatty acid (MUFA) and phenolic content ${ }^{(13)}$. 
The cardiometabolic health benefits of a MDP, first reported in the Seven Countries Study (SCS) in 1950's ${ }^{(14)}$, and are now well established ${ }^{(15-17)}$. An improved cardiometabolic phenotype is thought to in part underlie the emerging cognitive benefits of this dietary pattern. However, the majority of this evidence has been acquired from observational studies, such as European Prospective Investigation into Cancer-Norfolk (EPIC-Norfolk) ${ }^{(18)}$, with a dearth of randomised controlled trials (RCT) which report on the causal benefits of a MDP on long-term cognitive and overall mental health. The Prevencion con Dieta Mediterranea (PREDIMED) was the first RCT testing the long-term effectiveness of a MDP in primary prevention which had incidence of cardiovascular diseases as the primary point ${ }^{(19)}$. In a subgroup secondary analysis, the MDP interventions enriched with either EVOO or nuts were shown to improve cognitive function ${ }^{(20)}$ and depressive symptoms ${ }^{(21)}$. Available systematic reviews and meta-analysis focus on the long-term mental health benefits of a MDP, with adherence associated with an overall risk ratio of 0.79 (95\% CI, 0.70-0.90) of developing cognitive disorders ${ }^{(22)}$. Although no association was observed in the cohort analysis, data from 9 cross-sectional studies indicates a negative relationship between adherence to a MDP and risk of depression (odds ratio $=0.72 ; 95 \% \mathrm{CI}, 0.60-0.87)^{(23)}$.

In addition to the long-term trajectory, for the ever-increasing number of individuals with pre-existing cognitive or mental health deficits and even in healthy individuals, there is a great need and interest in identifying nutrition strategies which improve cognition, mood and anxiety in the short-term, in order to improve capabilities, independence and overall quality of life. Therefore, the objectives of the current systematic review are, (i) to conduct an evidence synthesis from RCT data to scrutinise whether a MDP has the potential to alter cognition, mood and mental wellbeing in the short-term, and (ii) identify research need and inform the design of future acute RCTs in the area. 


\section{Methods}

This systematic review was written in accordance with the Preferred Reporting Items for Systematic Reviews and Meta-Analyses (PRISMA) guidelines ${ }^{(24)}$. Our systematic review protocol is available on PROSPERO with the registration number CRD42021221085 ${ }^{(25)}$.

\section{Search strategy, eligibility criteria and study selection}

"Short-term" is defined as "up to 10 days" by discussions among the authors, where effects on cognition are likely to be mediated by rapidly responsive physiological processes such as brain blood flow, inflammation and oxidative status. Ovid EMBASE, Ovid MEDLINE and Web of Science Core Collection were searched ${ }^{(26,27)}$ from their inception dates to the 08 December 2020 by using keywords covering "Mediterranean diet", "olive oil", "cognition", "dementia", "mood", "mood disorders", “anxiety", “anxiety disorders", "depression", "depressive disorders" and "wellbeing". Free search terms and medical subject heading terms were combined where the databases allowed, namely EMBASE and MEDLINE. Final search strategies were constructed with the assistance of the academic librarian of the Faculty of Medicine and Health Sciences, University of East Anglia. The full electronic search string used in Ovid EMBASE is presented in Appendix 1.

Studies were accepted eligible if they;

- had an RCT design,

- intervened with either a MDP or EVOO,

- had an intervention period of up to and including 10 days,

- assessed either cognition, mood, anxiety or depression as a primary or secondary endpoint

- included adults over 18 years

- published in the English language.

Observational epidemiological studies were excluded. No gender filter was applied. The reference lists of included studies were manually read in order to obtain further potential publications. Two authors (LE and ESC) independently completed screening the titles and abstracts against the predefined eligibility criteria. Any discrepancies were resolved by 
discussions until an agreement was reached. EndNote $\mathrm{X} 9$ is used as the reference management tool.

\section{Definition of cognitive and mental health as the primary outcomes}

Cognition' is defined as "the mental action or process of acquiring knowledge and understanding through thought, experience and the senses" (28). Memory, attention, reasoning, decision making, visual and spatial abilities and behaviours are examples of 'cognitive functions'. Depression and anxiety are significant mood disorders, however, mild to moderate level of psychological stress can also cause substantial reductions in the quality of life. A variety of validated tools are available to assess cognition and mood, with details of the tools used in individual studies detailed below and in Table 1.

\section{Data extraction and quality assessment}

A table which recorded the authors, publication year, country that studies were conducted in, type of RCT, participant characteristics, study duration, intervention, main outcomes, assessment methods used, results (mental health status) and additional results/comments, was generated to extract the data from the included studies.

A quality assessment was done using RoB2, a revised tool for risk of bias by Cochrane ${ }^{(29)}$, which has five domains; bias arising from the randomisation process (D1), bias due to deviations from intended interventions (D2), bias due to missing outcome data (D3), bias in measurement of the outcome (D4), bias in selection of the reported result (D5) and plus overall bias (D6). The results of bias investigation are presented by means of a traffic light plot under low risk, some concerns or high risk.

\section{Data synthesis}

A narrative approach was used to synthesise the data. No quantitative analysis was performed due to the small number of studies. 


\section{Results}

\section{Study identification}

Initially, 3002 studies were obtained from the three electronic databases. After deduplication, 2261 studies remained, with 1721 from the MDP search and 540 from the EVOO search. Of these, 2253 were excluded following the title and abstract screening for reasons such as longer study durations, irrelevant outcomes, supplement interventions, epidemiological studies, animal studies, any type of reviews, meta-analysis and protocols. Full texts were screened for the remaining 8 studies. Finally, 4 studies, 3 full articles ${ }^{(30-32)}$ and 1 conference proceeding ${ }^{(33)}$, met the eligibility criteria, and were included. These 4 papers yielded a reference list of 85, which were scanned manually by LE and ESC, with no additional publications emerging for inclusion. The study identification process is presented in the PRISMA diagram (Figure 1).

\section{Study characteristics}

All included studies were RCTs, two with a cross-over ${ }^{(30,31)}$ and two with a parallel design ${ }^{(32,33)}$. All intervened with a MDP and were carried out in non-Mediterranean countries, two Northern European ${ }^{(30,33)}$ and two Australian ${ }^{(31,32)}$. The sample sizes ranged from $24^{(31)}$ to $53^{(33)}$. Three of the studies included young females only, with mean $( \pm$ standard deviation) ages, of $21.1 \pm 3.3^{(32)}, 22.3 \pm 3.7^{(33)}$ and $25.6 \pm 5.2^{(31)}$ years (mean \pm standard deviation). The remaining study ${ }^{(30)}$ included both males and females with metabolic syndrome traits with a participant mean age of $70 \pm 5$ years. None of the four RCTs reported any previous cognitive or mental health issues in the participants. Three had a study duration of 10 days, with one ${ }^{(30)}$ examining the physiological response 4.5 hours after the test meal. One study ${ }^{(30)}$ implemented a MDP alone or with a physical activity intervention (30 minutes moderate walking).

In terms of the MDP intervention, in one cross-over study ${ }^{(30)}$, participants were provided with their test breakfast $(4300 \mathrm{~kJ})$ that consisted of ciabatta, smoked salmon, muesli, fruit and vegetables which was described as rich in unsaturated fatty acids, dietary fibre and antioxidative compounds. The remaining three studies did not provide the study foods but rather guided participants in following a MDP. De Vries et al. ${ }^{(33)}$ did not provide 
any detail of the dietary instructions provided to participants. Lee et al. ${ }^{(31)}$ requested participants in the MDP group to increase their intake of fruit, vegetables, oily fish, low-fat dairy and nuts with a focus on healthy carbohydrates, fats and proteins, and to exclude meat, butter, margarine, caffeinated/energy drinks, added sugars and salts, alcohol, tobacco and illicit drugs during the study period. Besides, participants were also asked to consume freshly prepared foods and to avoid processed and packaged options where possible. Similarly, McMillan et al. ${ }^{(32)}$ asked participants to increase their consumption of fruits, vegetables, oily fish, low-fat dairy and nuts and to combine good sources of carbohydrates (less refined carbohydrates, whole grains, legumes, fruits and vegetables), fats and proteins. Additionally, they were instructed to abstain from red meat, refined sugars refined flour, pre-packaged and processed foods, caffeinated products, soft drinks and condiments.

Regarding dietary assessment methods, food diaries were used over the 10-day study period in order to record the dietary intake in three of the studies ${ }^{(31-33)}$. The remaining study provided the foods, so no self-reported dietary assessment was required ${ }^{(30)}$.

While three studies examined both mood and cognition as outcomes ${ }^{(30-32)}$, one study assessed only mood ${ }^{(33)}$. The assessment methods for mood included the German version of Multidimensional Mood State Questionnaire (MDMQ) ${ }^{(34)}$ for subjective mood (good/bad mood; alertness/fatigue and ease/unease) ${ }^{(30)}$, the Profiles of Mood States (POMS) questionnaires ${ }^{(35)}$ scoring the subscales tension/anxiety, fatigue/inertia, vigour/activity, confusion/bewilderment, anger/hostility, depression/rejection and the total mood disturbance score ${ }^{(31-33)}$ and the Bond-Lader visual analogue scales ${ }^{(36)}$ for the alertness, calmness and contentment ${ }^{(31-33)}$. For the assessment of cognition, the German version of the Frankfurt Attention Inventory 2 (FAIR-2, test version A) ${ }^{(37)}$ for attention ${ }^{(30)}$ and the Computerised Mental Performance Assessment System (COMPASS) ${ }^{(38)}$ battery for a variety of cognitive domains were used $^{(31,32)}$ (Table 1).

\section{Study quality}

The study quality assessment showed that all included studies have a low risk of bias in the first three domains ((D1), bias arising from the randomisation process; (D2) bias due to deviations from intended interventions; (D3), bias due to missing outcome data), while the 
other two domains ((D4) bias in measurement of the outcome and (D5) bias in selection of the reported result) were assessed as having some concerns (Figure 2).

\section{Primary outcome measures}

\section{Cognition:}

According to the COMPASS results, increased correct responses $(1.14, F=8.19$, $p=0.01)$ and decreased incorrect responses $(-0.32, F=4.83, p=0.04)$ were seen in immediate word recall; reduced incorrect responses $(-0.33, F=4.57, p=0.046)$ in delayed word recall were evident in the MDP group relative to the control while correct responses significantly decreased in MDP treatment $(-2.32, F=6.64, p=0.02)$ for the 3-back task ${ }^{(31)}$. Reaction time increased for numeric working memory task in MDP by $2 \%$ and decreased by $14 \%$ in the control group ( $F=5.05, p=0.04)$; reduced for Corsi Blocks task by 14\% (-420) in MDP treatment and increased by $27 \%(+837)$ in the control group $(F=17.628, p<0.001){ }^{(32)}$. Whilst reaction times reduced in the word recognition task in both arms, it was not significant in the $\operatorname{MDP}(3 \%,-29, p=0.574)$ treatment and significant in the control group $(20 \%,-191, p=0.001)$. The difference between the groups was significant $(F=5.04, p=0.035)^{(32)}$.

No overall significant effect of meal type in attention (as assessed by the FAIR-2 method) was recorded. However, in the walking groups a 1.4-fold increase was seen in the MDP group with compared to the WD, while this increase was 1.1-fold higher in the MDP relative to the WD in resting ( $p=0.045$ from iAUC data) ${ }^{(30)}$.

\section{Mood:}

Using the POMS questionnaire, vigour/activity $(p<0.001)$, tension/anxiety $(p=0.001)$, fatigue/inertia $(p=0.003)$, anger/hostility $(p=0.014)$, confusion/bewilderment $(p=0.015)$ and the total mood disturbance score ( $p$ value not stated) were significantly improved in the MDP arm compared to the control group ${ }^{(33)}$. Lowered confusion was observed by the MDP treatment $(-1.19, F=6.87, p=0.02)$ with no other changes in the subscales of mood evident (31). Following 10 days of MDP adherence, vigour rose by $18 \%(3.67, F=11.25, p=0.003)$ in the MDP condition with no other dimensions of mood significantly affected ${ }^{(32)}$. 
Using the Bond-Lader scale, alertness and contentment were improved by MDP in all 3 studies used this scale. The results were as follows; alertness $(p=0.003)$ and contentment $(p=0.001)^{(33)}$; alertness $(6.93, F=14.11, p<0.01)$ and contentment $(5.35, F=6.49, p<0.02)$ scores ${ }^{(31)}$; and alertness (16.43 (about 30\%), $\left.F=22.23, p<0.001\right)$ and contentment (12.89 (about 20\%), $F=16.634, p<0.001)^{(32)}$. No significant change was reported for calmness.

Using the MDMQ test, no main effect of meal type interventions was observed for $\operatorname{mood}{ }^{(30)}$.

\section{Secondary outcome measures}

Two of the studies reported dietary adherence. In the Lee et al.'s study ${ }^{(31)}$, all of the participants $(\mathrm{n}=24)$ an average MDP adherence of $94 \%$ was evident which ranged from $80 \%$ to $100 \%$. Similarly, in the McMillan et al.'s study ${ }^{(32)}$, a mean MDP adherence of $93 \%$ for meals (range $80 \%$ to $100 \%$ ) and $95 \%$ for snacks (85\% to $100 \%)$ was reported.

No significant impact of a MDP meal vs WD meal on plasma cortisol levels was evident ${ }^{(30)}$. Only Lee et al. assessed the impact of intervention on blood pressure, blood flow velocity and arterial stiffness ${ }^{(31)}$. A significant decrease $(-1.05, F=6.15, p=0.02)$ in augmentation pressure $(\mathrm{mm} \mathrm{Hg})$ was observed in the MDP condition relative to the control group.

Diekmann et al. assessed the desire to eat ${ }^{(30)}$. The overall hunger was not influenced by meal while satiety was higher after MDP as compared to the WD $(p<0.001)$.

Body weight and body mass index (BMI) were tracked in two of the studies. Lee et al. ${ }^{(31)}$ reported a significant weight loss in the MDP $(-1.77 \mathrm{~kg}, F=10,81, p<0.01)$ group. McMillan et al. ${ }^{(32)}$ observed no significant main effect of diet on body weight, BMI or waist circumference (WC) between the two groups. 


\section{Discussion}

This is the first systematic review to report the short-term effects of a MDP on cognition and overall mental well-being. The findings suggest that a MDP has the potential to affect cognition and mood in as little as 10-days. The findings have also identified important research gaps notably; there are few reported studies and of the studies available most were conducted in young people, aged 18 to 38 years ${ }^{(31-33)}$ and all conducted in individuals without cognitive or mental health complaints. In addition, there was a tendency to study females with only 18 males in the 128 participants from the 4 studies. Therefore, the shortterm effect of a MDP on mental health status in older adults, and in particular individuals who present with evidence of cognitive or mental health decline, is currently unknown.

Specific cognitive domains improved in all of the studies assessing the cognition although the findings were not consistent ${ }^{(30-32)}$. Attention was significantly improved after the MDP in one study, with the authors speculating that this difference may be caused by the higher glucose content of the MDP (carbohydrate content of the meals: $133 \mathrm{~g}$ in MDP vs 93.7 $\mathrm{g}$ in WD) as the brain uses glucose as the primary source of energy ${ }^{(30)}$. Other studies reported improvements in immediate and delayed memory recall tasks, working memory and reaction times ${ }^{(31)}$, and spatial working memory ${ }^{(32)}$. Consistent with these short-term effects, previous studies have reported longer-term ( 8 weeks) effects of a MDP enriched with dairy foods on processing speed in adults at above average CVD risk in the MedDairy study ${ }^{(39)}$.

Mood dimensions, namely, alertness and contentment, were significantly and consistently improved by MDPs in the short-term in all four studies. Vigour ${ }^{(32,33)}$ and confusion ${ }^{(31,33)}$ were also improved following the MDP. Adherence to a MDP has previously been shown to be associated with reduced risk of depression in elderly ${ }^{(40)}$ and in the MedDairy study, a reduction in depression, tension, anger, confusion and total mood disturbance score were recorded following the 8 weeks dietary intervention period ${ }^{(39)}$. Furthermore, polyphenols intake, which are considered an important bioactive in the plant based MDP, have shown to reduce depressive symptoms ${ }^{(41)}$.

Previous short-term studies using other dietary intervention or health endpoints provide insight into the possible mechanistic basis for the effect of a MDP on mental health. Myette-Côté et al. ${ }^{(42)}$ examined the effects of a low fat, low glycaemic index diet (GL), to a 
low carbohydrate diet (LC) or a low carbohydrate plus post-meal walking (LC+Ex), in type 2 diabetes on glucose levels and inflammatory factors in a RCT comprising of three 4-days interventions. While improved glycaemic control was evident in the LC group, plasma monocyte-derived microparticles (MMP) reduced significantly in the GL group which was similar to a MDP, suggesting that cerebral hypometabolism and inflammation which are features of cognitive disorders may be positively modulated by short-term dietary strategies. Attuquayefio et al. ${ }^{(43)}$ reported a decrease in hippocampal-dependent learning and memory (HDLM) following a breakfast high in saturated fat, cholesterol and added sugar and low in protein relative to an isocaloric healthy breakfast for 4 consecutive days, findings which were subsequently confirmed over a one-week intervention period ${ }^{(44)}$. The hippocampus is a core brain area for cognitive functions such as learning and memory ${ }^{(45)}$. Besides, the hippocampus is involved in anxiety-related behaviours ${ }^{(46)}$ and major depression ${ }^{(47)}$. This evidence suggests the hippocampus function can be affected negatively by an unhealthy eating pattern in as short period as 4 days.

The hippocampus also produces high concentrations of brain-derived neurotrophic factor (BDNF) which is important in attention, cognition and total behaviour ${ }^{(48)}$. Decreased levels of BDNF have been linked to cognitive and mood disorders, and it has been identified as a therapeutic target in neurodegenerative and psychiatric impairments ${ }^{(49)}$. In the PREDIMED study, a MDP raised BDNF levels over 3 years whilst a MDP supplemented with nuts was linked to significant improvement in serum BDNF levels in individuals with depression ${ }^{(50)}$. However, the existing literature does not provide any insight into the shortterm impacts of a MDP on BDNF levels.

Blood brain barrier (BBB) is a dynamic selective interface between the brain and the bloodstream, in which dysregulations are associated with cognitive (including AD) and psychiatric disorders ${ }^{(51)}$. Although selected dietary components have been shown to affect BBB function such as permeability in animal models ${ }^{(52)}$ and the BBB is susceptible to be impairment by a WD ${ }^{(53)}$, the impact of a MDP in short- or long-term mental health is currently unknown but should be a focus of investigation. Additionally, a reduction in cerebral blood flow (CBF) is associated with cognitive dysfunction ${ }^{(54)}$. Lamport et al. ${ }^{(55)}$ investigated the impacts of high flavanones on cognition and CBF in young healthy participants in an acute RCT. A high flavanone citrus juice resulted in a two hour increase in $\mathrm{CBF}$ and better performance in one cognitive task (Digit Symbol Substitution) were observed 
in the experimental group. McManus et al. ${ }^{(56)}$ examined the acute effects of eicosapentaenoic acid (EPA) or docosahexaenoic acid (DHA), found in oily fish, on arterial stiffness in men at high risk of CVD. Four hours following to the test meal, vascular function was significantly improved by the DHA-rich oil. Besides, a MDP is known to chronically affect systematic vascular function ${ }^{(57)}$.

The influences of the gut microbiota on cognition and overall mental well-being are well-recognised $^{(58,59)}$. Therefore, nutritional strategies targeting the gut health may represent a meaningful strategy for delaying or even reversing neuropathology ${ }^{(60)}$. David et al. ${ }^{(61)}$ demonstrated that the gut microbiota can be changed through both animal-based and plantbased diets in 5-days. Moreover, in a 1-year longitudinal study, the gut microbiota responded to daily changes in diet ${ }^{(62)}$. Hence, accumulating evidence suggests that the gut-brain axis could mediate the even short-term effects of a MDP on cognition and mental wellbeing.

The current review highlighted that all of the participants in the MDP treatments from the two studies tracking dietary adherence ${ }^{(31,32)}$ reported high dietary adherence with no side effects. Besides, a MDP was linked to higher satiety in one study ${ }^{(30)}$ and significant weight loss despite no caloric restriction in the another study ${ }^{(31)}$. Considering the fact that maintenance of healthy eating behaviours is not an easy task even in the short-term, this available evidence suggests that a MDP is an acceptable implementable approach even in non-Mediterranean countries.

The review has also highlighted a lack of consistency in how the MDP is applied. Despite the small number of included studies, none of them used the same dietary procedure although the two Australian studies gave similar instructions to their participants $(31,32)$. Abdelhamid et al. ${ }^{(63)}$ have previously reported the high inconsistencies in food and nutrient intake through when adopting a MDP. Davis et al. ${ }^{(64)}$ also reported discrepancies in how the MDP was defined and the resulting nutrient intakes, with vegetable intakes, for example, ranged from 191-500 g/day in high MDP adherers. A greater standardisation in the definition of a MDP is needed in order to integrate data from difference sources and translate it in dietary recommendations focussed on improved short- and long-term health.

The main strength of the present paper is that it is the first systematic review to examine the short-term impact of a MDP on mood and cognition. Secondly, the database 
combination used ensured optimal coverage of the data ${ }^{(26,27)}$, and has been shown by others to retrieve $95.9 \%$ of available references ${ }^{(26)}$. Third, the review covers all available literature up to Dec 2020. As for limitations, the number of studies found was small, therefore, the conclusions are preliminary rather than robust. However, this limitation provided an opportunity to identify research gaps. The second limitation is the high heterogeneity in the dietary and mental health status assessments used. This methodological variability restricted making comparisons between studies.

In conclusion, the possible short-term beneficial impacts of a MDP on cognitive and mental health have been reviewed systematically for the first time. The results provide some initial evidence that short-term dietary interventions can confer health benefits which directly and/or indirectly improve cognitive and mental health. However, future studies are required to elucidate which cognitive and other mental health domains could be beneficially affected and what are the underlying physiological mechanism mediating the effects. Short-term strategies to improve cognition, mood and anxiety are not only of interest to improve quality of life and capabilities in those with existing mental health deficit but also in healthy individuals. The definition of the MDP in future studies should be carefully considered, with attention given to its population adoption taking into account social, geographical and cultural mediators of eating behaviours.

Acknowledgements: We would like to thank to Lee Hooper, RD, $\mathrm{PhD}$, an expert in systematic reviews, and Matthew Smith, the academic librarian of the Faculty of Medical and Health Sciences, University of East Anglia, for their contributions throughout the review.

Financial Support: LE is financially supported by the Ministry of National Education, The Republic of Turkey. Our ongoing (AMM and AJ) research programmes at UEA on the MDP and cognitive health are funded by Alzheimer's Research UK (ARUK, PRRF2017-006), MRC (MR/T001852/1) and the ESRC (ES/S010408/1). KJM and AMM are chief investigators on a National Health and Medical Research Council funded research programme looking at the cognitive benefits of a MDP+walking in older Australian adults (NHMRC, APP1171300). 
Conflict of Interest: None to report

Authorship: AMM and KJM formulated the research question. LE and ESC conducted the systematic review of the literature, $\mathrm{LE}$ and $\mathrm{AJ}$ conducted the risk of bias analysis. AMM, AJ and LE interpreted the data. LE drafted the manuscript with all authors contributing to the manuscript ad approving the final version.

Ethical Standards Disclosure: NA 


\section{References}

1. Nichols E, Szoeke CE, Vollset SE et al. (2019) Global, regional, and national burden of Alzheimer's disease and other dementias, 1990-2016: a systematic analysis for the Global Burden of Disease Study 2016. The Lancet Neurology 18, 88-106.

2. Statistics OfN (2020) Leading causes of death, UK.

3. Prince M, Wimo A, Guerchet M et al. (2015) The global impact of dementia. World Alzheimer Report, 1-82.

4. Petersen RC (2016) Mild cognitive impairment. CONTINUUM: Lifelong Learning in Neurology 22, 404.

5. Jessen F, Amariglio RE, Buckley RF et al. (2020) The characterisation of subjective cognitive decline. The Lancet Neurology 19, 271-278.

6. Jessen F, Amariglio RE, van Boxtel M et al. (2014) A conceptual framework for research on subjective cognitive decline in preclinical Alzheimer's disease. Alzheimer's \& Dementia 10, 844-852.

7. (WHO) WHO (2017) Depression and Other Common Mental Disorders, Global Health Estimates.

8. James SL, Abate D, Abate KH et al. (2018) Global, regional, and national incidence, prevalence, and years lived with disability for 354 diseases and injuries for 195 countries and territories, 1990-2017: a systematic analysis for the Global Burden of Disease Study 2017. The Lancet 392, 1789-1858.

9. Livingston G, Sommerlad A, Orgeta V et al. (2017) Dementia prevention, intervention, and care. The Lancet 390, 2673-2734.

10. Jennings A, Cunnane SC Minihane AM (2020) Can nutrition support healthy cognitive ageing and reduce dementia risk? bmj 369.

11. Willett WC, Sacks F, Trichopoulou A et al. (1995) Mediterranean diet pyramid: a cultural model for healthy eating. The American journal of clinical nutrition 61, 1402S-1406S.

12. Visioli F, Franco M, Toledo E et al. (2018) Olive oil and prevention of chronic diseases: Summary of an International conference. Nutrition Metabolism and Cardiovascular Diseases 28, 649-656.

13. Gorzynik-Debicka M, Przychodzen P, Cappello F et al. (2018) Potential Health Benefits of Olive Oil and Plant Polyphenols. International Journal of Molecular Sciences 19. 
14. Kromhout D, Menotti A, Bloemberg B et al. (1995) Dietary Saturated and transFatty Acids and Cholesterol and 25-Year Mortality from Coronary Heart Disease: The Seven Countries Study. Preventive Medicine 24, 308-315.

15. Bendall CL, Mayr HL, Opie RS et al. (2018) Central obesity and the Mediterranean diet: A systematic review of intervention trials. Critical Reviews in Food Science and Nutrition 58, 3070-3084.

16. Kastorini C-M, Milionis Haralampos J, Esposito K et al. (2011) The Effect of Mediterranean Diet on Metabolic Syndrome and its Components. Journal of the American College of Cardiology 57, 1299-1313.

17. de Lorgeril M, Salen P, Martin J-L et al. (1999) Mediterranean Diet, Traditional Risk Factors, and the Rate of Cardiovascular Complications After Myocardial Infarction. Circulation 99, 779-785.

18. Shannon OM, Stephan BCM, Granic A et al. (2019) Mediterranean diet adherence and cognitive function in older UK adults: the European Prospective Investigation into Cancer and Nutrition-Norfolk (EPIC-Norfolk) Study. American Journal of Clinical Nutrition 110, 938-948.

19. Martínez-González MÁ, Corella D, Salas-Salvadó J et al. (2012) Cohort Profile: Design and methods of the PREDIMED study. International Journal of Epidemiology 41, 377-385.

20. Martinez-Lapiscina EH, Clavero P, Toledo E et al. (2013) Mediterranean diet improves cognition: The PREDIMED-NAVARRA randomised trial. Journal of Neurology, Neurosurgery and Psychiatry 84, 1318-1325.

21. Sanchez-Villegas A, Martinez-Gonzalez MA, Estruch R et al. (2013) Mediterranean dietary pattern and depression: The PREDIMED randomized trial. BMC Medicine 11, 208.

22. Wu L \& Sun DL (2017) Adherence to Mediterranean diet and risk of developing cognitive disorders: An updated systematic review and meta-analysis of prospective cohort studies. Scientific Reports 7.

23. Shafiei F, Salari-Moghaddam A, Larijani B et al. (2019) Adherence to the Mediterranean diet and risk of depression: a systematic review and updated metaanalysis of observational studies. Nutrition Reviews 77, 230-239.

24. Liberati A, Altman DG, Tetzlaff J et al. (2009) The PRISMA statement for reporting systematic reviews and meta-analyses of studies that evaluate health care 
interventions: explanation and elaboration. Journal of Clinical Epidemiology 62, e1e34.

25. Esgunoglu L CE, Jennings A, Murphy K, Minihane AM (2021) Short-term effects of a Mediterranean-style dietary pattern and olive oil on cognition, mood and mental wellbeing: a systematic review of clinical trials. PROSPERO: University of York.

26. Bramer WM, Rethlefsen ML, Kleijnen J et al. (2017) Optimal database combinations for literature searches in systematic reviews: a prospective exploratory study. Systematic Reviews 6, 245.

27. Gusenbauer M \& Haddaway NR (2020) Which academic search systems are suitable for systematic reviews or meta-analyses? Evaluating retrieval qualities of Google Scholar, PubMed, and 26 other resources. Research synthesis methods 11, 181-217.

28. Dictionary OE Cognition. In LEXICO powered by Oxford.

29. Sterne JAC, Savović J, Page MJ et al. (2019) RoB 2: a revised tool for assessing risk of bias in randomised trials. $B M J 366,14898$.

30. Diekmann C, Wagner M, Huber H et al. (2019) Acute impact of dietary pattern and walking on postprandial attention, mood, and satiety in older adults: A randomized crossover trial. Nutrients 11, 2294.

31. Lee J, Pase M, Pipingas A et al. (2015) Switching to a 10-day Mediterranean-style diet improves mood and cardiovascular function in a controlled crossover study. Nutrition 31, 647-652.

32. McMillan L, Owen L, Kras M et al. (2011) Behavioural effects of a 10-day Mediterranean diet. Results from a pilot study evaluating mood and cognitive performance. Appetite 56, 143-147.

33. De Vries E, Van Schrojenstein Lantman M, Hoebregts V et al. (2017) Mediterranean diet and mood. European Neuropsychopharmacology 27, S879-S880.

34. Steyer R, Schwenkmezger P, Notz P et al. (1994) Testtheoretische Analysen des Mehrdimensionalen Befindlichkeitsfragebogen (MDBF). Diagnostica.

35. McNair D, Lorr M Droppleman L (1971) Manual for the profile of mood states (POMS). San Diego: Educational and Industrial Testing Service.

36. Bond A \& Lader M (1974) The use of analogue scales in rating subjective feelings. British Journal of Medical Psychology 47, 211-218.

37. Petermann F (2011) Frankfurter Aufmerksamkeits-Inventar 2 (FAIR-2). Zeitschrift für Psychiatrie, Psychologie und Psychotherapie 59, 325-326. 
38. Scholey A, Ossoukhova A, Owen L et al. (2010) Effects of American ginseng (Panax quinquefolius) on neurocognitive function: an acute, randomised, double-blind, placebo-controlled, crossover study. Psychopharmacology 212, 345-356.

39. Wade AT, Davis CR, Dyer KA et al. (2020) A Mediterranean diet supplemented with dairy foods improves mood and processing speed in an Australian sample: results from the MedDairy randomized controlled trial. Nutritional Neuroscience 23, 646658.

40. Masana MF, Haro JM, Mariolis A et al. (2018) Mediterranean diet and depression among older individuals: The multinational MEDIS study. Experimental Gerontology $110,67-72$.

41. Bayes J, Schloss J Sibbritt D (2020) Effects of Polyphenols in a Mediterranean Diet on Symptoms of Depression: A Systematic Literature Review. Advances in Nutrition $11,602-615$.

42. Myette-Côté É, Durrer C, Neudorf H et al. (2018) The effect of a short-term lowcarbohydrate, high-fat diet with or without postmeal walks on glycemic control and inflammation in type 2 diabetes: a randomized trial. American Journal of PhysiologyRegulatory, Integrative and Comparative Physiology 315, R1210-R1219.

43. Attuquayefio T, Stevenson RJ, Oaten MJ et al. (2017) A four-day Western-style dietary intervention causes reductions in hippocampal-dependent learning and memory and interoceptive sensitivity. PLOS ONE 12, e0172645.

44. Stevenson RJ, Francis HM, Attuquayefio T et al. (2020) Hippocampal-dependent appetitive control is impaired by experimental exposure to a Western-style diet. Royal Society Open Science 7, 191338.

45. Driscoll I, Hamilton DA, Petropoulos H et al. (2003) The Aging Hippocampus: Cognitive, Biochemical and Structural Findings. Cerebral Cortex 13, 1344-1351.

46. Bannerman DM, Rawlins JNP, McHugh SB et al. (2004) Regional dissociations within the hippocampus-memory and anxiety. Neuroscience \& Biobehavioral Reviews 28, 273-283.

47. MacQueen GM, Campbell S, McEwen BS et al. (2003) Course of illness, hippocampal function, and hippocampal volume in major depression. Proceedings of the National Academy of Sciences 100, 1387.

48. Yeom C-W, Park Y-J, Choi S-W et al. (2016) Association of peripheral BDNF level with cognition, attention and behavior in preschool children. Child and Adolescent Psychiatry and Mental Health 10, 10. 
49. Teixeira AL, Barbosa IG, Diniz BS et al. (2010) Circulating levels of brain-derived neurotrophic factor: correlation with mood, cognition and motor function. Biomarkers in Medicine 4, 871-887.

50. Sanchez-Villegas A, Galbete C, Martinez-Gonzalez MA et al. (2011) The effect of the Mediterranean diet on plasma brain-derived neurotrophic factor (BDNF) levels: the PREDIMED-NAVARRA randomized trial. Nutritional neuroscience 14, 195-201.

51. Kealy J, Greene C Campbell M (2020) Blood-brain barrier regulation in psychiatric disorders. Neuroscience Letters 726, 133664.

52. Youdim KA, Shukitt-Hale B Joseph JA (2004) Flavonoids and the brain: interactions at the blood-brain barrier and their physiological effects on the central nervous system. Free Radical Biology and Medicine 37, 1683-1693.

53. Hsu TM \& Kanoski SE (2014) Blood-brain barrier disruption: mechanistic links between Western diet consumption and dementia. Frontiers in Aging Neuroscience 6.

54. Mattsson N, Tosun D, Insel PS et al. (2014) Association of brain amyloid- $\beta$ with cerebral perfusion and structure in Alzheimer's disease and mild cognitive impairment. Brain 137, 1550-1561.

55. Lamport DJ, Pal D, Macready AL et al. (2016) The effects of flavanone-rich citrus juice on cognitive function and cerebral blood flow: an acute, randomised, placebocontrolled cross-over trial in healthy, young adults. British Journal of Nutrition 116, 2160-2168.

56. McManus S, Tejera N, Awwad K et al. (2016) Differential effects of EPA versus DHA on postprandial vascular function and the plasma oxylipin profile in men. Journal of lipid research 57, 1720-1727.

57. Shannon OM, Mendes I, Köchl C et al. (2020) Mediterranean Diet Increases Endothelial Function in Adults: A Systematic Review and Meta-Analysis of Randomized Controlled Trials. The Journal of Nutrition 150, 1151-1159.

58. Foster JA \& McVey Neufeld K-A (2013) Gut-brain axis: how the microbiome influences anxiety and depression. Trends in Neurosciences 36, 305-312.

59. Proctor C, Thiennimitr P, Chattipakorn N et al. (2017) Diet, gut microbiota and cognition. Metabolic Brain Disease 32, 1-17.

60. Bischoff SC (2016) Microbiota and aging. Current Opinion in Clinical Nutrition \& Metabolic Care 19.

61. David LA, Maurice CF, Carmody RN et al. (2014) Diet rapidly and reproducibly alters the human gut microbiome. Nature 505, 559-563. 
62. David LA, Materna AC, Friedman J et al. (2014) Host lifestyle affects human microbiota on daily timescales. Genome Biology 15, R89.

63. Abdelhamid A, Jennings A, Hayhoe RPG et al. (2020) High variability of food and nutrient intake exists across the Mediterranean Dietary Pattern-A systematic review. Food Science \& Nutrition 8, 4907-4918.

64. Davis C, Bryan J, Hodgson J et al. (2015) Definition of the Mediterranean Diet; a Literature Review. Nutrients 7, 9139-9153. 
Table 1. Study details and main outcomes

\begin{tabular}{|c|c|c|c|c|c|c|c|c|c|c|c|}
\hline Authors & $\begin{array}{l}\text { Publica } \\
\text { tion } \\
\text { year }\end{array}$ & $\begin{array}{l}\text { Countr } \\
\text { y }\end{array}$ & $\begin{array}{l}\text { Type of } \\
\text { RCT }\end{array}$ & $\begin{array}{l}\text { Participan } \\
\text { t } \\
\text { characteri } \\
\text { stics }\end{array}$ & $\begin{array}{l}\text { Duratio } \\
\text { n }\end{array}$ & $\begin{array}{l}\text { Interven } \\
\text { tion }\end{array}$ & $\begin{array}{l}\text { Main } \\
\text { outcom } \\
\text { es }\end{array}$ & $\begin{array}{l}\text { Assessme } \\
\text { nt } \\
\text { methods } \\
\text { used }\end{array}$ & $\begin{array}{l}\text { Additional } \\
\text { outcomes }\end{array}$ & $\begin{array}{l}\text { Results } \\
\text { (Mental Health } \\
\text { Status) }\end{array}$ & $\begin{array}{l}\text { Additional } \\
\text { results/co } \\
\text { mments }\end{array}$ \\
\hline $\begin{array}{l}\text { Diekman } \\
\text { n et al. } \\
\text { (29) }\end{array}$ & 2019 & $\begin{array}{l}\text { German } \\
\text { y }\end{array}$ & $\begin{array}{l}\text { Cross- } \\
\text { over }\end{array}$ & $\begin{array}{l}\mathrm{n}=26 \\
8 \text { Female, } \\
18 \text { Male } \\
\text { Metabolic } \\
\text { syndrome } \\
69.9 \pm 4.7 \\
\text { years* } \\
\text { BMI }=30.3 \\
\pm 2.3 \\
\mathrm{~kg} / \mathrm{m}^{2} *\end{array}$ & $\begin{array}{l}4.5 \\
\text { hours } \\
2 \text { weeks } \\
\text { wash- } \\
\text { out } \\
\text { periods }\end{array}$ & $\begin{array}{l}4 \\
\text { interventi } \\
\text { ons } \\
\text { (isoenerg } \\
\text { etic, } 4300 \\
\mathrm{~kJ} / \mathrm{meal} \text { ): } \\
\\
\text { 1.WD + } \\
\text { walking } \\
2 . \mathrm{WD}+ \\
\text { resting } \\
\text { 3.MDP + } \\
\text { walking } \\
\text { 4.MDP + } \\
\text { resting }\end{array}$ & $\begin{array}{l}\text { Mood } \\
\text { Cogniti } \\
\text { on }\end{array}$ & $\begin{array}{l}\text { MDMQ } \\
(34) \\
\text { FAIR-2 } \\
(37)\end{array}$ & $\begin{array}{l}\text { Appetite } \\
\text { Plasma } \\
\text { cortisol } \\
\text { levels }\end{array}$ & $\begin{array}{l}\text { MDMQ: No effect } \\
\text { of diet } \\
\text { FAIR-2: Walking } \\
\text { group: } 1.4 \text {-fold } \\
\text { increase in } \\
\text { attention in MDP } \\
\text { compared to WD. } \\
\text { Resting group: } \\
\text { 1.1-fold increase } \\
\text { in attention in } \\
\text { MDP compared to } \\
\text { WD. (p=0.045 } \\
\text { from iAUC data, } \\
\text { meal x time } \\
\text { interaction NS). }\end{array}$ & $\begin{array}{l}\text { No effect } \\
\text { of diet on } \\
\text { cortisol } \\
\text { VAS: No } \\
\text { impact of } \\
\text { diet on } \\
\text { hunger. } \\
\text { Satiety was } \\
\text { higher after } \\
\text { MDP } \\
\text { compared } \\
\text { to the WD } \\
(p<0.001) \text {. }\end{array}$ \\
\hline
\end{tabular}




\begin{tabular}{|c|c|c|c|c|c|c|c|c|c|c|c|}
\hline & & & & & & & & & & $\begin{array}{l}\text { rment }(p=0.015) \\
\text { and the total mood } \\
\text { disturbance score } \\
\text { ( } \mathrm{p} \text { not stated), and } \\
\text { contentment } \\
(p=0.001) ; \\
\text { alertness } \\
(p=0.003) \text { in MDP } \\
\text { compared to } \\
\text { control group. } \mathrm{p} \\
\text { values are for the } \\
\text { time*treatment } \\
\text { interactions, no } \\
\text { effect sizes are } \\
\text { presented. }\end{array}$ & $\begin{array}{l}\text { the control } \\
\text { group diet. }\end{array}$ \\
\hline$\underset{(30)}{\text { Lee } e t a l .}$ & 2015 & Australia & $\begin{array}{l}\text { Cross- } \\
\text { over }\end{array}$ & $\begin{array}{l}\mathrm{n}=24 \\
\text { Female } \\
\text { Healthy } \\
25.6 \pm 5.1 \\
\text { years* }\end{array}$ & 10 days & $\begin{array}{l}\text { MDP or } \\
\text { NC }\end{array}$ & $\begin{array}{l}\text { Mood } \\
\text { Cogniti } \\
\text { on }\end{array}$ & $\begin{array}{l}\text { POMS } \\
\text { (35) } \\
\text { Bond- } \\
\text { Lader }{ }^{(36)} \\
\text { COMPA } \\
\text { SS }^{(38)}\end{array}$ & $\begin{array}{l}\text { Cardiovasc } \\
\text { ular } \\
\text { function: } \\
\text { blood } \\
\text { pressure, } \\
\text { blood flow } \\
\text { velocity } \\
\text { and arterial } \\
\text { stiffness } \\
\text { Dietary } \\
\text { adherence } \\
\text { Anthropo } \\
\text { metric } \\
\text { measures }\end{array}$ & $\begin{array}{l}\text { Confusion reduced } \\
\text { in MDP }(-1.19) \\
\text { and increased } \\
(1.52) \text { in NC. } \\
(F=6.87, p=0.02) \text {. } \\
\text { Alertness } \\
\text { increased in MDP } \\
(6.93) \text { and reduced } \\
\text { in NC }(-8.31) \\
(F=14.11, p<0.01) \text {. } \\
\text { Contentment } \\
\text { increased in the } \\
\text { MDP group }(5.35) \\
\text { and reduced in NC } \\
(-4.23) .(F=6.49, \\
p<0.02) .\end{array}$ & $\begin{array}{l}\begin{array}{l}\text { Food } \\
\text { diaries } \\
\text { were used } \\
\text { over } 10 \\
\text { days. }\end{array} \\
\text { Augmentati } \\
\text { on pressure } \\
\text { (mm Hg) } \\
\text { reduced in } \\
\text { MDP (- } \\
1.05) \text { and } \\
\text { increased } \\
\text { in NC } \\
(0.95) \\
(F=6.15, \\
p=0.02) .\end{array}$ \\
\hline
\end{tabular}




\begin{tabular}{|c|c|c|c|c|c|c|c|c|c|c|c|}
\hline & & & & & & & & & & $\begin{array}{l}\text { Immediate word } \\
\text { recall: Correct } \\
\text { responses } \\
\text { increased in MDP } \\
(1.14) \text { and reduced } \\
\text { in NC }(-0.64) \\
(F=8.19, p=0.01) \text {. } \\
\text { Incorrect } \\
\text { responses } \\
\text { decreased in MDP } \\
(-0.32) \text { and } \\
\text { increased in NC } \\
(0.36)(F=4.83, \\
p=0.04) . \\
\text { Delayed word } \\
\text { recall: Incorrect } \\
\text { responses } \\
\text { decreased in MDP } \\
(-0.33) \text { and } \\
\text { increased in } \mathrm{NC} \\
(0.71)(\mathrm{F}=4.57, \\
\text { p=0.046). } \\
3 \text {-back task: } \\
\text { Correct responses } \\
\text { reduced in the } \\
\text { MDP }(-2.32) \text { and } \\
\text { increased in } \mathrm{NC} \\
(4.14)(F=6.64, \\
p=0.02) .\end{array}$ & $\begin{array}{l}100 \% \\
\text { dietary } \\
\text { adherence } \\
\text { to MDP } \\
\text { BW: } \\
\text { Reduced in } \\
\text { MDP group } \\
(-1.77 \mathrm{~kg}) \\
\text { and } \\
\text { increase in } \\
\text { NC group } \\
(0.11) \\
(F=10,81 \text {, } \\
p<0.01) \text {. } \\
\text { No change } \\
\text { in BMI }\end{array}$ \\
\hline $\begin{array}{l}\text { Mc } \\
\text { Millan et } \\
\text { al. } \\
(31)\end{array}$ & 2011 & Australia & $\begin{array}{l}\text { Parallel } \\
\text { arms }\end{array}$ & $\begin{array}{l}\mathrm{n}=25 \\
\text { Female }\end{array}$ & 10 days & $\begin{array}{l}\text { MDP or } \\
\text { NC }\end{array}$ & $\begin{array}{l}\text { Mood } \\
\text { Cogniti } \\
\text { on }\end{array}$ & $\begin{array}{l}65 \text {-item } \\
\text { POMS } \\
\text { (35) }\end{array}$ & $\begin{array}{l}\text { Dietary } \\
\text { adherence } \\
\text { Anthropo }\end{array}$ & $\begin{array}{l}\text { Vigour increased } \\
\text { in MDP by } 18 \% \\
(3.67) \text { and reduced } \\
\text { in NC by } 22 \%(-\end{array}$ & $\begin{array}{l}\text { Food } \\
\text { diaries } \\
\text { were used } \\
\text { over } 10\end{array}$ \\
\hline
\end{tabular}




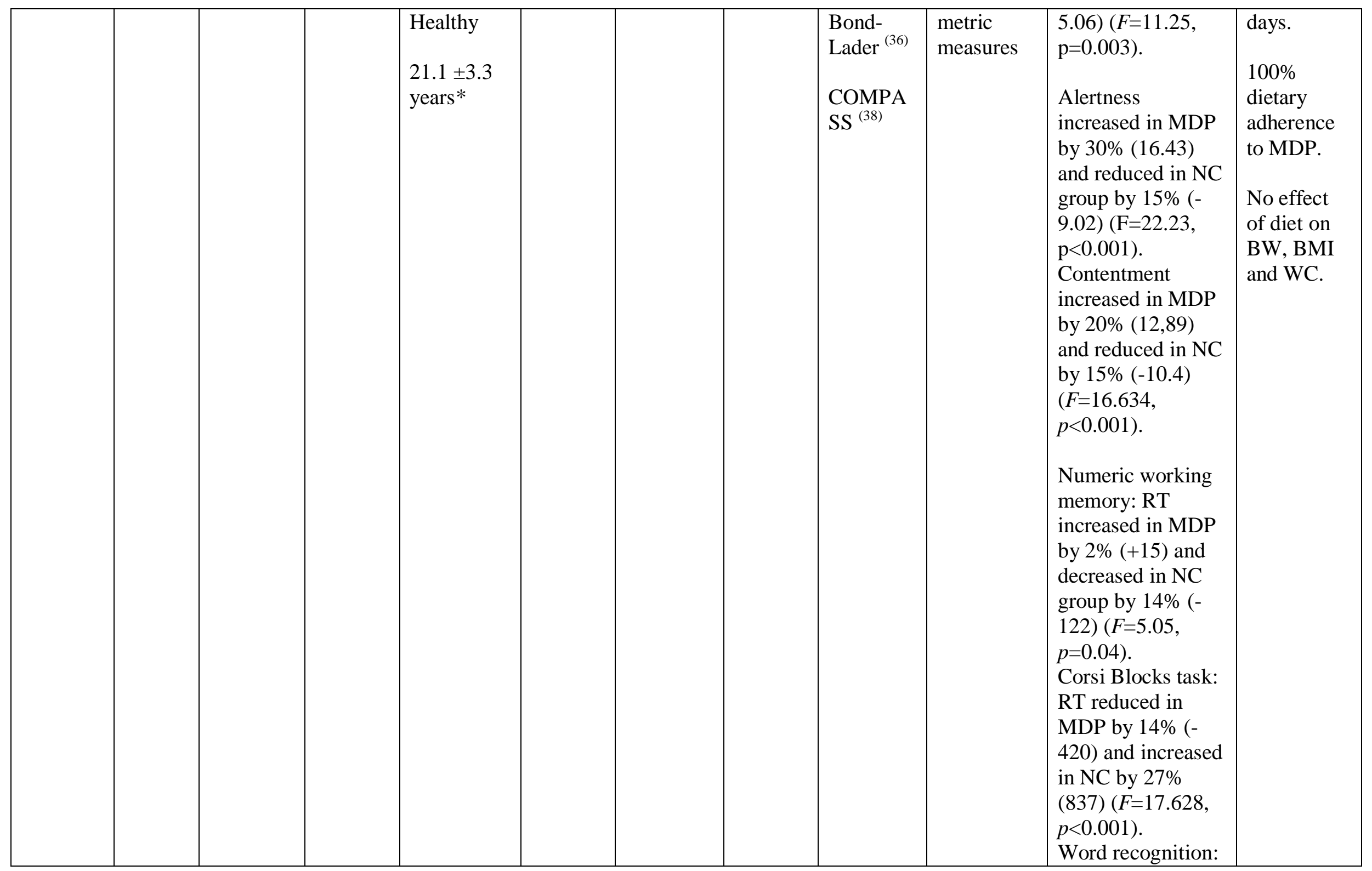




\begin{tabular}{|l|l|l|l|l|l|l|l|}
\hline & & & & & & & \\
RT reduced in \\
MDP by 3\% (-29) \\
$(p=0.574$, NS) and \\
in the NC by 20\% \\
$(-191)(p=0.001)$. \\
The difference \\
between groups \\
was significant: \\
$(F=5.04, p=0.035)$.
\end{tabular}

Asterisk $\left(^{*}\right)$ represents mean \pm standard deviation unless otherwise stated. RCT: Randomised controlled trial; BMI: Body Mass Index; kJ/meal: kilojoule/meal; WD: Western diet that is rich in total fat, saturated fatty acids and animal protein; MDP: Mediterranean-style dietary pattern; MDMQ: Multidimensional Mood State Questionnaire for mood; FAIR-2: Frankfurt Attention Inventory-2 for cognition; iAUC: Area under the curve; NS: Not significant; VAS: Visual Analogue Scale for hunger, appetite and satiety; POMS: Profile of Mood States questionnaire for mood (tension/anxiety, anger/hostility, fatigue/inertia, vigour/activity, confusion/bewilderment, depression/rejection and total mood disturbance score); Bond Lader Scale for mood (alertness, contentment and calmness); NC: No change in diet; COMPASS: The Computerised Mental Performance Assessment System for cognitive domains; RT: Reaction time; BW: Body weight; WC: Waist circumference. 
Accepted manuscript
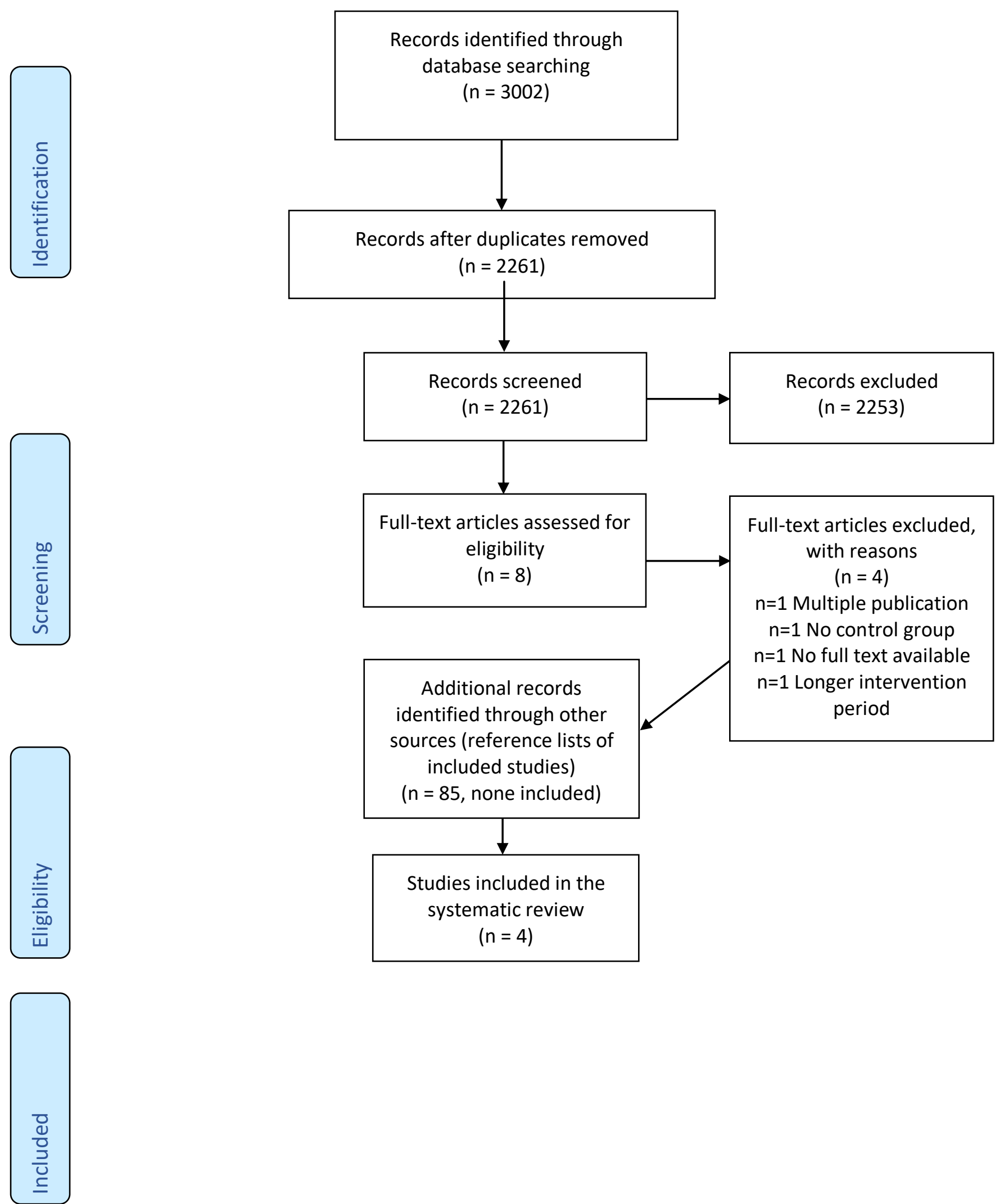

Figure 1. PRISMA flow diagram 


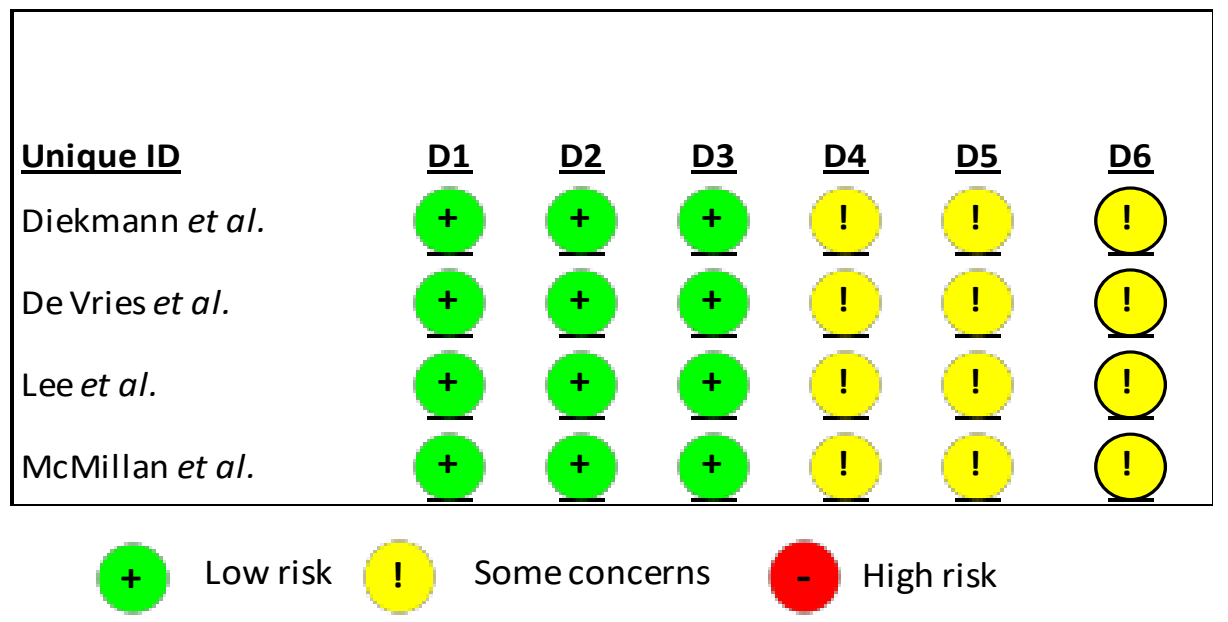

D1: bias arising from the randomisation process; D2: bias due to deviations from intended interventions; D3: bias due to missing outcome data; D4: bias in measurement of the outcome; D5: bias in selection of the reported result; D6: overall bias.

Figure 2. Risk of bias assessment results 